\title{
NEW ZEALAND'S APPROACH TO PARALLEL IMPORTED GOODS AND THE COPYRIGHT AMENDMENT ACT 1998
}

\author{
Matthew J Coull
}

The prohibition against parallel importing has attracted growing international attention, especially given the global trend towards freeing up international trade. This paper examines New Zealand's new statutory provisions relating to parallel importing following the Copyright Amendment Act 1998. This Act legalises parallel importing in New Zealand in given circumstances. The paper critically assesses the economic arguments for parallel importing to analyse whether these support the rationale behind the amendment. It then questions whether the potential defects in the pre-amendment law were sufficiently severe to warrant the fundamental policy reversal effected by the Act, and discusses alternative avenues of reform and whether these are viable in New Zealand. Underlying the discussion is a consideration of whether the same law should apply to all types of goods, and whether New Zealand's approach should focus more rigorously on the varying characteristics of individual markets.

\section{NEW ZEALAND'S APPROACH TO PARALLEL IMPORTING}

\section{A The Statutory Regime}

Parallel importing occurs where goods that have been legally manufactured overseas and which contain intellectual property rights, are imported into the New Zealand market without the permission of the New Zealand intellectual property right owner. New Zealand has historically prohibited parallel importing through sections 12 and 35 of the Copyright Act 1994 (the Act). These were retained following the 1994 revision of the Act.

This is an edited version of a paper submitted in fulfilment of the VUW LLB (Hons) legal writing requirement. 
The Copyright (Removal of Prohibition on Parallel Importing) Amendment Act 1998 represents a reversal in policy. It retains sections 12 and 35 , but amends section $12 .{ }^{1}$ It effectively reverses section 12(3)(a)'s previous meaning. It creates an exception to the definition of "infringing copy", removing the prohibition on parallel imported goods if either of new subsections (5A)(a) or (b) are met. Subsection (5A)(a) permits parallel importing in most cases where the products are manufactured by the copyright owner, or with the copyright owner's consent in the country in which they were made. Subsection $(5 \mathrm{~A})(\mathrm{b})$ deals with "quasicounterfeit" goods - those products which are produced "legally" only because a country may not recognise copyright protection. In this situation the products may be imported only if one of the requirements in subsection $(5 \mathrm{~A})(\mathrm{b})(\mathrm{i})$ - (iv) is satisfied: the copyright period has expired, no one has attempted to secure copyright protection for the product, the object is a three dimensional object that has been industrially applied in terms of section 75(4) of the Copyright Act, or the object was made in that country with the consent of the New Zealand copyright owner. If a product does not fall within subsection (5A), it remains prohibited as an infringing copy under section $12(3)(\mathrm{b}) .^{2}$

The Explanatory Note to the Copyright Amendment Bill states: "[t]he Bill changes the Copyright Act to make New Zealand goods markets more competitive, and to ensure that New Zealanders are paying internationally competitive prices for goods".

On this view, the amendment appears to be driven by consumer welfare and economic rationale. It also implies that intellectual property rights are being used as a political tool. This observation reflects the view discussed in Part III that copyright may be a conceptually inappropriate mechanism to prevent parallel importing. Using copyright to prevent parallel importing was not initially implemented to increase prices; therefore removing the restrictions to achieve lower prices should not be done at the expense of sacrificing copyright interests. This argument is valid until one accepts that copyright laws are also used to facilitate international price discrimination. If this is accepted, then using economic justifications to abandon the prohibition does not represent an arbitrary reduction in the scope of intellectual property rights. It is consistent with the conclusion that intellectual property rights were being overextended.

1 Copyright Amendment Act 1998, s 5(2).

2 Inconveniently, the Copyright Amendment Act 1998 switches the parallel importing provision in s 12. The 1994 parallel importation provision was s 12(3)(a). Following the Copyright Amendment Act, it is now s $12(3)(b)$. 


\section{NEW ZEALAND'S INTERNATIONAL TRADE AND INTERNATIONAL INTELLECTUAL PROPERTY OBLIGATIONS}

The Copyright Amendment Act is unlikely to breach any of New Zealand's formal international intellectual property obligations. No international intellectual property treaties or obligations compel signatories to prohibit parallel importing. The United States threatened trade retaliation in response to the Copyright Amendment Act, on the basis that New Zealand had breached its obligations under the GATT Agreement. To date, no such action has eventuated. In reality, the United States' concern is the potential precedent effect of New Zealand's policy decision. ${ }^{3}$

\section{WAS THE CHANGE NECESSARY? - ECONOMIC AND POLICY ARGUMENTS}

\section{A Traditional Justifications of Parallel Importing}

Authorised distributors argue that restrictions on parallel imports encourages local manufacturing in New Zealand through the absence of price competition. Advocates of parallel importing emphasise claims of positive overall economic welfare effects to counter balance the job losses.

Interest groups often argue that parallel importing will retard development of local authors and culture through reduced offshore funding. This effect may be real, but theoretically at least, it can be argued that if local artists are to be supported, the assistance should be sourced directly through a government agency and not through an in-substance subsidy at the expense of domestic consumers. Allowing parallel importing will not reduce returns to the copyright owner, nor will it reduce the incentive to innovate.

The overseas copyright owner will still receive royalties from the market in which the product was first sold. On-selling from the first market does not directly reduce the return to the copyright owner. Also, New Zealand's relative economic size would have little impact on incentives of the overseas entity to innovate.

3 Neither the TRIPS Agreement, the World Trade Organisation Trade Related Aspects of Intellectual Property Rights, Annex 1C to the World Trade Organisation Agreement, Uruguay, 1993 of which New Zealand is a signatory, nor the WIPO Copyright Treaty, World Intellectual Property Organisation Diplomatic Conference on Certain Copyright and Neighbouring Rights Questions, WIPO Copyright Treaty, Geneva, 1996, of which New Zealand is not a signatory, require prohibition. 


\section{B Consumer Interests and Protection}

\section{Price discrimination}

Incentives to parallel import only exist if prices in the market of importation are higher than at least one international alternative market. This may result from several factors, including exchange rate fluctuations and production cost differences. It may also arise from the copyright owner practising international market segregation, which, provided it does not infringe competition law, is a legitimate contractual instrument available to copyright owners. Combined with a prohibition on parallel importing, market segregation operates to allow authorised distributors to charge artificially high prices.

The Ministry of Commerce commissioned a report ("the Report") from the New Zealand Institute of Economic Research ${ }^{4}$ ("NZIER"), which conducted an empirical analysis of the effect of section 35 on three different New Zealand markets - books, music compact discs and motor vehicles. The Report found that "because of the differentiation between copyright products, each seller has a degree of market power which may prevent the consumer from enjoying the lowest possible prices." 5 In other words, inter brand competition alone is unlikely to eliminate the ability to price discriminate, as the copyright itself prevents substitutes from being too close. Even if price discrimination is possible in New Zealand, removing parallel importing restrictions will not affect prices if the price differences are exclusively due to production cost differences. The Report acknowledged the difficulty of distinguishing between the two without internal information. It is, however, indicative of the existence of price discrimination that lobby groups such as the music industry claim that consumers are not paying excessive prices, ${ }^{6}$ yet are the same groups which oppose the amendment and claim that removing the prohibition will lead to a substantial level of parallel importing.

Although the Report was inconclusive on the existence of price discrimination, attacking such discrimination appears to be the key motivation behind the Copyright Amendment Act 1998.

4 New Zealand Institute of Economic Research Parallel Importing: A Theoretical And Empirical Investigation (Wellington, 1998) ["Parallel Importing: A Theoretical And Empirical Investigation"].

$5 \quad$ Parallel Importing: A Theoretical And Empirical Investigation above $\mathrm{n} 4$ (ii).

6 "Manufacturers Fear Damage From Parallel Importing Move" The Dominion, Wellington, 18 May 1998, 16 


\section{Technical and post sales support}

Authorised distributors take the view that parallel importers are able to undercut them on price partly through not offering comprehensive warranties or after sales service.

If parallel importers provide insufficient information to allow consumers to distinguish their goods from the authorised distributors' goods, consumers purchasing from the importer (at a lower price) may not realise they are ineligible for the local authorised distributor's "free" servicing facilities. ${ }^{7}$ Therefore, consumers may not be making an informed choice as to whether they purchase such support. If so, the uninformed consumers may suffer, through having to meet such costs themselves. ${ }^{8}$ Therefore, parallel importing may damage both the local distributor's goodwill and the brand's reputation. Many products however, such as compact discs, require only minimal post sales servicing.

\section{Consumer deception}

Authorised distributors argue that parallel importing will generate further consumer deception. As manufacturers make products "market specific", parallel imported goods may be unsuitable for the New Zealand market, and consumers may purchase these goods thinking they have features that they do not.

These arguments have some force, although less so where the parallel importer has a long term interest in the markets. Clear labelling requirements, notifying consumers of potential differences of parallel imported products already exist. At any rate such difficulties are more appropriately dealt with under the relevant competition law or consumer law regime, than under intellectual property laws.

7 Such service would not be free, since it is included in their selling price, whereas the parallel importer's price may exclude the value of such services.

8 It is unclear to what extent a manufacturer or authorised distributor will be willing to repair products with defects that have been purchased from parallel importers. The need to maintain brand reputation is a powerful one. For a more detailed discussion, see Alan Dick "Car Firms Move To Block Parallel Imports" The Independent, Wellington, 1 July 1998, 34. The Consumer Guarantees Act 1993 may also apply if the goods are defective. 


\section{Consumer safety}

Intellectual property right owners argue that protection of consumer safety is a justification for maintaining restrictions. ${ }^{9}$ This reasoning is less compelling because the goods are genuine. Conceptually, consumer safety should not be a justification to support a parallel importing prohibition. It is more appropriately dealt with under regulatory safety inspections and customs checks.

\section{The Free Rider Debate}

Authorised distributors argue that parallel importers free ride on their promotional and marketing efforts, benefiting from the demand created for a product without incurring advertising costs themselves. ${ }^{10}$

Free rider arguments overlook the fact that it is also in the importers' interests to engage in brand maintenance and increase sales through marketing. However, parallel importers may be prohibited from advertising the imported product by the Trademarks Act 1953, if the advertisement imports a reference to the trademark owner or their products. ${ }^{11}$ Authorised distributors can also reduce the potential for "free riding" by making their advertising dealer specific. $^{12}$

The Report strengthened the rebuttal of free rider arguments in the New Zealand book and compact disc markets, concluding there was no significant advertising carried out by the authorised distributors. ${ }^{13}$ However, it found there were "legitimate concerns about consumers of nearly new parallel imported vehicles free riding on the warranty provisions provided by

9 For example, inadequate service documentation regarding a vehicle's service history, and the difficulty in tracing parallel imported products in the event of a recall. David John "Car Imports" National Business Review, Wellington, New Zealand, May 23 1997, 22.

10 Qing Lu Parallel Importation - Abuse of Intellectual Property Rights, Legislative Responses: A Comparative Survey, LLM Thesis, VUW, 1992, 29.

11 Trademarks Act 1953 s 8(1A)(a) and (e). This may depend on what exactly is registered and advertised, but advertising will generally be difficult, especially if the brand name itself is a registered trade mark.

12 Richard Andrade "The Parallel Importing of Unauthorised Genuine Goods: Analysis and Observations of the Gray Market" (1993) 14 U Penn J Int'l Bus Law 409, 428 ["Observations of the Gray Market"].

13 Parallel Importing: A Theoretical And Empirical Investigation above n 4, 49, 58. 
the domestic agent."14 This highlights a practical distinction between functional and nonfunctional goods. ${ }^{15}$

\section{Economic Efficiency}

\section{Distribution monopolies}

Prohibiting parallel imports creates a distribution monopoly. ${ }^{16}$ This potentially inflates prices and therefore creates economic efficiency losses. As parallel imports provide competition absent from inter-brand and secondhand competition alone, this may create efficiency gains to the advantage of domestic industry and consumers. The Report's findings in this respect are discussed in Part V.

\section{Bundling of services}

Authorised distributors may argue that as the costs of the post-sales support are high, parallel importing could reduce the authorised distributor's sales volume and profitability to the point of making the authorised distributorships untenable. Thus, all domestic consumers would face reduced access to servicing and parts.

This argument is really that authorised distributors need to be able to cross-subsidise their sales revenue through their post-sales service takings. This is called "bundling". This argument is unconvincing. It fails to recognise that many goods require post-sales support regardless of the source of purchase. ${ }^{17}$ Authorised distributors providing such service should simply increase their charges for servicing goods purchased from parallel importers. This opportunity exists for functional goods to differing degrees depending on the degree of postsales support required. The Report found that New Zealand's experience of parallel importing in the used car market, "where such services are important, suggests that competition may, in

14 Parallel Importing: A Theoretical And Empirical Investigation above n 4, 33.

15 See Part IV, A, 2.

16 This situation did not contravene the provisions of the Commerce Act 1986 regarding monopoly positions. Section 36 of the Commerce Act prohibits the use of a dominant market position to prevent competition in a market. Authorised distributors do not fall within this prohibition, as they are generally not in a position of market dominance. This is because alternative suppliers of an alternative product exist.

17 It also ignores the fact that many products do not require post-sales service at all. 
fact, improve after-sales service."18 Initially, although difficulties in obtaining spare parts existed, an industry quickly emerged.

If consumers value full post-sales servicing and "peace of mind" they will purchase through an authorised distributor. This argument relies on consumers being aware that parallel importers' prices may exclude some services offered by the authorised distributors. Parallel importing can therefore promote economic efficiency, providing consumers with a market oriented choice.

Several of the arguments considered in this Part advocate separate consideration based on the product's degree of functionality. Such a distinction reinforces the claim that "an economic analysis would not necessarily produce the same answers for all markets...the nature and extent of [the] problems are critically dependant on the specific features of different markets."19 This view is considered in more detail below.

\section{ADEQUACY OF THE PRE-EXISTING LAW}

The economic arguments above help affirm that New Zealand has adopted the correct approach, but are not conclusive. The Copyright Amendment Act was passed without being considered by a select committee or being available for public submission. The adequacy of the existing framework to protect the competing interests should be investigated to evaluate the wisdom behind the amendment.

\section{A Is Copyright an Appropriate Mechanism to Prevent Parallel Imports, and if so, Should it Protect Functional Goods?}

\section{Typical copyright protection}

As an important function of copyright has become to protect and encourage innovation and creativity, it is argued that copyright is an inappropriate mechanism to deal with parallel importing. This is because "the right to move intellectual property goods across national boundaries is not a core intellectual property right. It provides distribution monopolies rather than protection for the intellectual property itself." ${ }^{\prime 2}$ The Report concluded that parallel

18 Parallel Importing: A Theoretical And Empirical Investigation above n 4, (ii).

19 Chairman of the Australian Price Surveillance Authority [PSA] in Stephen Corones "Parallel Importing Computer Software: Consumer Welfare Considerations" (1992) 3 AIPJ 188, 198.

20 Abraham van Melle "Why Parallel Importing Makes Good Sense Despite US Anger" National Business Review, Wellington, New Zealand, 22 May 1998, 20. 
importing restrictions are only useful if they enhance the incentive to innovate. It stated that while useful to prevent pirated goods entering the country and to help the distributor maintain quality and reputation through exclusivity, these are not the primary purposes of the importing prohibitions. It concluded that these objectives should be addressed through noncopyright means. ${ }^{21}$ Copyright law also may not be the most appropriate mechanism through which to address health and safety issues. On this view, an absence of legitimate copyright concerns is embodied in the reasons for abandoning the prohibition.

The arguments justifying the prohibition seldom focus on protecting typical copyright interests. This was stated by Ian McDonald, Legal Officer of the Australian Copyright Council, when commenting on submissions to restrict Australia's parallel importing laws: ${ }^{22}$

It is notew orthy that these submissions are not argued from bases that have been the traditional concerns of copyright law: the encouragement of learning, or the protection of author's livelihoods...or the protection of creative skill and effort... Rather, copyright is relied upon to protect brand reputation, product safety and consumer interests.

The Copyright Amendment Act is consistent with these comments.

\section{Functionality of goods}

The economic arguments assessed in Part III highlighted the fact that the product's degree of functionality impacts on the strength of the economic justifications for parallel importing restrictions. In general, the greater the degree of functionality, the less compelling the economic justification for the prohibition. As the economic justifications decline, so too do intellectual property justifications. Using copyright to restrict distribution of functional goods can produce intriguing results. As van Melle put it "...if a sculpture by Moore is protectable, then so is a Volvo car door panel." ${ }^{23}$ However, the Act itself protects "artistic works", which includes a

21 Parallel Importing: A Theoretical And Empirical Investigation above n 4, 61.

22 Ian McDonald "Bailey's, Bottles and Bills: the Copyright Amendment Bill 1997 and the Parallel Importing of Labels And Packaging" (1997) 31 Intellectual Property Forum 14, 19 ["Bailey's, Bottles and Bills"].

23 Abraham van Melle "Copyright Laws Not Working In The Interests Of Car Buyers" National Business Review, Wellington, New Zealand, 16 May 1997, 23. 
graphic work or model. ${ }^{24}$ Functional items attract copyright protection in their graphics, in the underlying sketches, in the design of the parts, or in models or prototypes. ${ }^{25}$

It is easier to argue that granting copyright protection does encourage development and creativity in terms of the functional product's design if the underlying design sketches attract copyright. This argument cannot logically be extended to mere decorative graphics. It means the distribution of potentially all manufactured goods can be manipulated by adding copyright material to the article itself. This is a conceptual inadequacy in the existing law, but one which could be solved without needing to abolish the prohibition totally. It is addressed by Australian legislation, discussed in Part V below.

\section{B Digital Technology and the Internet: Are Continued Parallel Importation Restrictions Futile in the Future?}

The ability to purchase products directly over the internet may render parallel importing laws ineffective. The ability to control distribution of copyright works is reduced, since the nature of the internet eliminates the relevance of geography to such distribution. ${ }^{26}$ "Internet orders" are generally filled by overseas wholesalers, who are not concerned with the publisher's distribution practices, and will supply a work even if it is available domestically. This would probably not occur if the publisher filled the orders itself. An individual's "internet order" would most likely fall within the "private and domestic" exception under section 35, but if significant quantities of individual orders occur in the future, this will have the same effect on authorised distributors as commercial orders. Removing the restriction may allow retailers to source products more cheaply and remain competitive with internet suppliers.

In light of the internet's capability to cross national boundaries, parallel importing laws may become redundant for copyright works that are capable of being reduced to digital form, such as literary and musical works. Copies can be downloaded from a site in another country, without going through the local authorised distributor. For instance, the availability of

24 Copyright Act 1994 ss 2, 14(1).

25 Wham-O MFG Co v Lincoln Industries [1984] 1 NZLR 641; Bonz Group (Pty) Ltd v Cooke [1994] 3 NZLR 216. Artistic merit is not a requirement for copyright protection in these cases.

26 Distribution cost explanations as a basis for pricing differences will also cease to be relevant. 
cyberspace jukeboxes for musical works "displaces the need for copies themselves."27 This would also fall within the private and domestic exception.

At such an early stage of the internet's development, it may be unwise to conclude that parallel importing laws cannot cope with digitisation and internet sales. Internet issues have yet to be satisfactorily addressed internationally, and at present, these arguments in isolation cannot be legitimate reasons to reduce the prohibition. An alternative view is that although the NZIER report stated, "most New Zealand households do not have access to the internet", 28 these arguments to remove parallel importing restrictions are theoretically and practically valid, and will be increasingly so in the future.

\section{Should the Prohibition Apply to Secondhand/Used Goods?}

\section{The judicial interpretation}

The pre-Copyright Amendment Act law had been criticised for preventing parallel importation of secondhand goods. In Composite Developments (NZ) Ltd v Kebab Capital Ltd ${ }^{29}$ the authorised distributor successfully brought an injunction prohibiting the parallel importation of secondhand skis. Salmon J held there was an arguable case that section 12 extended to include secondhand goods in the prohibition, as "[g]iving an ordinary meaning to the words used in s 12 that appears to be a necessary consequence." 30 Although not decided at a substantive hearing, the result was followed in Lyntec Holdings $v$ Wills, ${ }^{31}$ which prevented the importation of secondhand jetskis.

\section{Was this approach inappropriate?}

On a literal reading, the Act's wording could support the Composite Developments result, but it has been argued that (the former) section 12 was not interpreted in the appropriate policy context. ${ }^{32}$ The Composite Developments interpretation gave authorised distributors exclusive

27 Tony Chance "After the Copyright Act 1994: The Music Industry Moves Into the Digital Age" (1996) 1(5) NZIPJ 112, 115.

28 Parallel Importing: A Theoretical And Empirical Investigation above n 4, 57.

29 Composite Developments (NZ) Ltd v Kebab Capital Ltd (1996) 7 TCLR 186 ["Composite Developments"].

30 Composite Developments above n 29, 190 per Salmon J.

31 Lyntec Holdings Ltd v Wills (29 January 1997) unreported, High Court, Auckland Registry, CP 11/97.

32 Philip Culbert "Casenote: Composite Developments (NZ) Ltd v Kebab Capital Ltd " (1997) 1(7) NZIPJ 174, 175. 
power to control the entire market for that product. While consistent with the (pre-1998 amendment) objective of section 35, it reaffirmed the authorised distributor's ability to maintain price levels artificially high. It can be argued from a policy perspective that the Act was not clear enough to adopt such an extreme stance of territoriality. This issue may not have even been considered by Parliament before the 1994 revision of the Act, although a trade mark case which prevented parallel importing of secondhand goods was decided in New Zealand in 1989. 33 Consequently, the legislature may have implicitly continued to include secondhand goods in the restriction by not explicitly excluding them from the scope of section 35 in the 1994 revision.

Authorised distributors will argue that the Composite Developments approach must be correct, for the reason that if secondhand goods were excluded from the (pre-1998 amendment) prohibition, this would provide an easy mechanism for importers to circumvent the restriction for new goods. That is, if the prohibition were confined to "new" goods, it would lose its efficacy. ${ }^{34}$ If secondhand (used) goods were to escape the prohibition, incentives would clearly exist for importers to "sell" the goods to an associated party, such as a relative or subsidiary company. Technically, the goods become secondhand, even after a minimal amount of use, but retain a large proportion of their value. "Nearly new" parallel imported "secondhand" goods would dramatically undermine the authorised distributor's pricing mechanism. Including secondhand goods in the (former) prohibition therefore removes such "backdoor" methods of avoiding the (pre-1998 amendment) section 35 prohibition for new goods.

Unfortunately for authorised distributors, this argument is relatively easily defeated by redefining "used". A threshold based on age, as opposed to usage avoids the problems outlined above. For example, a framework could be implemented to permit the parallel importing of secondhand goods that are at least two years old. This balances both parties' interests, as the distributor remains able to benefit from the initial hype of a new product, and obtain a satisfactory return on its investments (copyrights or licences). The parallel importer is able to enter the market later to facilitate competition. This solution can be regarded as a practical compromise, and would mean an importing restriction could exclude secondhand goods. Registry, CP 346/89 [South Pacific Tyres].

34 The Act does not explicitly use the word "new". "Secondhand" can only be logically interpreted as meaning "used", as in a sale to an end consumer, not simply movement along a distribution chain. The Act is unclear on this point. 
This analysis suggests that prohibiting parallel importation of secondhand goods per se may have been unnecessary. Although the prohibition on parallel importation of secondhand goods under the pre-Copyright Amendment Act attracted criticism, this wide scope did not render the pre-Copyright Amendment Act law unworkable.

\section{Parallel Importing Where Goods Are Unavailable Domestically}

A product may be unavailable on the local market either because no authorised distributor has been appointed, or the copyright owner has not imported it itself. In this situation, parallel importers argue that the absence of any other importer justifies their importing the goods. It is important to note that intellectual property rights will still belong to a foreign copyright owner regardless of whether the product is sold in the country of importation or not. It is in this context that the issue of implied licence arises.

\section{The pre-Copyright Amendment Act statutory context}

Before the Copyright Amendment Act, if importation occurred without a licence, section 35 was infringed. Parallel importers do not possess an express licence to import, and must argue that they have an implied licence. The relevant argument became whether an implied licence could exist in New Zealand. Section 35 does not require an express licence.

At common law, licences may be implied, but only in quite specific circumstances. In Ozi Soft Pty Ltd $v$ Wong ${ }^{35}$ at the time the parallel importing occurred, the authorised distributor had not imported the product, which was therefore unavailable in the domestic market. Einfeld J noted the fundamental problem that: ${ }^{36}$

[i]t may be that some other mechanism needs to be developed to resolve these issues, because the interests of the Australian people in having free access to literary, musical and artistic works... are adversely affected if oppressive restrictions on importation and sale may be imposed by copyright owners who are not themselves importing or intending to import the works in question.

The refusal to infer an implied licence was upheld on appeal. Even where the goods are unavailable, many inferential facts are needed to imply a licence, such as the identities and intentions of the relevant parties, any prior dealings, and the quantities of the goods involved.

35 Ozi Soft Pty Ltd $v$ Wong (1988) 10 IPR 520 [Ozi Soft].

36 Ozi Soft above n 32 at 525. See also Abraham van Melle "Parallel Importing Developments in Lyntec Holdings and Remington Arms Company" (1997) 1(8) NZIPJ 199, 205 [Parallel Importing Developments]. 
The threshold for an implied licence to exist is high, and a lack of domestic supply does not meet it.

\section{The (pre-Copyright Amendment Act) New Zealand position}

Remington Arms Company Inc v Reloaders Supplies ${ }^{37}$ complicated the issue in New Zealand. Remington had appointed Sportways as its exclusive distributor in New Zealand. The products were available domestically, but the issue regarding availability of goods arose where Master Gambrill stated: ${ }^{38}$

Regardless of the circumstances surround[ing] the sale of the goods to the Defendants and regardless of whether the Plaintiffs do or do not impose restrictions on sale, the Plaintiffs have a legitimate cause of action...

This statement seemed to reject the possibility of any implied licence existing, even where no authorised distributor was appointed. The rigidity of this approach ignored the circumstances surrounding the sale, and has been criticised as too stringent. ${ }^{39}$ Applied literally, it was more severe than Ozi Soft. The potential for an implied licence should not have been dismissed too quickly, for consumer welfare reasons, at least until an authorised distributor was appointed. Ozi Soft did not reject the potential for an implied licence so categorically. To hold that implied licences were irrelevant per se was a substantial restriction given the wording of section 35 itself. The Remington position is, however, consistent with the fact that in New Zealand copyright goods, including parallel imports, are not subject to compulsory licences merely because the goods are unavailable in New Zealand.

Therefore, as the law stood before the Copyright Amendment Act, importers could not assume that either the absence of a distribution chain or the absence of a product from the market due to the appointed authorised distributor not importing it, allowed parallel importing through an implied licence. This extreme position meant foreign manufacturers or local authorised distributors could deliberately restrict or delay the availability of products to New Zealand consumers. ${ }^{40}$ This may be a matter of the manufacturers' freedom of choice, but

37 Remington Arms Company Inc v Reloaders Supplies Ltd (20 December 1996) unreported, High Court, Auckland Registry, CP 384/95 ["Remington"].

$38 \quad$ Remington above $\mathrm{n} 37,18$.

39 "Parallel Importing Developments" above n 36, 203.

40 Such as importing only high specification luxury models to maintain a reputation of quality. 
has potential for excessive application. Such a constricting position supports the arguments of proponents of abandoning the prohibition. It is suggested, however, that an amendment similar to the Australian Copyright Amendment Act 1991, could alleviate this issue. The preamendment law, while again extreme, was not irreparable.

\section{AN ALTERNATIVE APPROACH - THE AUSTRALIAN WAY}

Australia has addressed many of the above arguments incrementally, while maintaining the general prohibition. Its parallel importation restrictions are implemented through sections 37 and 38 of the Copyright Act 1968 (Cth).

\section{A Access to Imported Goods}

Australian copyright reform began through the Copyright Amendment Act 1991. This inserted section 44A into the Copyright Act and allowed the parallel importation of books into Australia if, within 30 days of being published overseas, the book was not available in Australia through the authorised distributor. This amendment is a concession to increasing consumer access to books. In itself, this does not conceptually abandon the rationale underlying the parallel importing laws. It represents an incremental approach, addressing availability issues as they arise.

The amendment was based on the recommendations of the Australian Price Surveillance Authority (PSA), which found that Australians paid higher prices and suffered more limited availability of titles than other countries. ${ }^{41}$ The PSA recognised this was partly due to Australia being a small and geographically isolated market.

This amendment recognises that parallel importing restrictions should not be used to justify prohibiting the importation of goods that are unavailable in the country of importation. The same type of amendment could be applied in New Zealand. It would help alleviate the implications arising from Remington, and therefore reduce some of the tensions on the implied licence doctrine. This is especially relevant where the authorised distributor has not attempted to import the article in question. The viability of New Zealand adopting such an amendment is discussed further in Part VI.

41 Price Surveillance Authority Inquiry into Book Prices - Final Report (Canberra, Australia, December 1989) 50. 


\section{B Packaging and Labelling}

Arguments discussed earlier regarding functional items demonstrated that parallel importing restrictions can operate in ways that do not reflect the object or intent of copyright law. Bailey $v$ Boccaccio Pty Ltd ${ }^{42}$ demonstrates this point in another way. Copyright in a bottle's label, an artistic work, was used to prevent the parallel importation of bottles bearing that label. This decision illustrated the over-extension of protection against importation, leading to the comment that "[h]owever imaginatively labelled or packaged a bottle of liquor may be, the product is liquor." 43

\section{The Australian reaction - enacted amendments}

Section 44B was inserted into the Copyright Act 1968 in $1994 .{ }^{44}$ This amendment allows parallel importing to the limited extent that copyright in the writing ${ }^{45}$ on a label on a container of a chemical product could not be used to prevent importation. The Copyright Amendment Act $1998^{46}$ relaxes the prohibition where the copyright material is contained in a label or packaging. This extends section 44B to include consumer goods, "to prevent copyright on product packaging being used by distributors to create exclusive markets." 47 This is a conceptual removal, not a concession to availability, as with books.

Under the Australian Copyright Amendment Act 1998, if a product contains copyright only in an "accessory" which usually accompanies consumer goods, parallel importation cannot be prevented on that basis alone. The amendment seems broad, as the definition of "accessory" includes a label (either on the article or the relevant container), the packaging or container itself, and any written instructions, warranty or other information provided with the article. ${ }^{48}$

42 Bailey E Co v Boccaccio Pty Ltd (1984-1986) 6 IPR 279.

43 Senate Legal and Constitutional Legislation Committee Consideration of Legislation Referred to the Committee: Copyright Amendment Bill 1997 (Department of the Senate, Parliament House, Canberra, 1997), 64. Cited in "Bailey's, Bottles and Bills" above n 22, 19.

44 By the Agricultural and Veterinary Chemicals (Consequential Amendments) Act 1994.

45 The relaxation is limited, as it only relates to writing, not pictures. Writing is defined as a mode of representing or reproducing words, figures or symbols in a visible form.

46 The Act received royal assent on 30 July 1998.

47 "Bailey's, Bottles and Bills" above n 22, 18.

48 "Bailey's, Bottles and Bills" above n 22, 19. Copyright Act 1968, s 10(1). 
Whether terms such as "label", "packaging" or "container" are interpreted broadly or narrowly will determine how potent the Amendment Act becomes. A broad interpretation is necessary for the amendment to achieve its purpose, and it seems logical that future judicial interpretation should support this.

\section{Analysis of the Australian amendments}

These amendments address potentially extreme results that are inconsistent with commercial reality. The ability to add a simple label to a product should not in itself bestow extra "benefits" on the product that would otherwise not attach. Being able to merely add a label makes it a simple matter to circumvent the rationale of the parallel importing law, especially for functional objects. Therefore, merely adding a label is an effective mechanism for the manufacturer/copyright owner to achieve protection. The product could be imported without the label, as this is where the copyright lies, but removing the label destroys the product's marketability.

Now that an exception is being made in relation to labels, the Australian legislature is acknowledging that artificial devices (such as labels) have been used to over-extend copyright protection. Arguments may arise as to why the relaxation should stop at labels and why could it not extend to decorative graphics on functional items. This argument is attractive in theory, but may have no practical effect if copyright attaches to other parts of these goods, such as the design of components.

The Australian Copyright Amendment Act would not permit parallel importing of the goods in Composite Developments or Lyntec. This is because it is unlikely that decorative graphics would fall within the definition of "accessory". Even if the amendment was extended as suggested above, products such as jet skis would probably have copyright protecting the design of their components.

Although copyright law may no longer prohibit parallel importing of goods with such packaging, trademark law still might. This is considered further in Part VII. If trademark law 
does restrict parallel importing, a packaging type amendment will only be effective to the extent that the goods do not bear a trade mark, or bear one that is easily removed. ${ }^{49}$

\section{Sound Recordings}

The Copyright Amendment Act (No 2) $1998^{50}$ allows parallel importing of "non-infringing" sound recordings. It is therefore comparable to New Zealand's Copyright Amendment Act 1998. The Senate Legal and Constitutional Committee (SLCC) recommended the Bill be passed, but qualified this by recommending that the government investigate the effect the Bill may have on composers where a work containing their work is imported from a country which does not recognise copyright. ${ }^{51}$ The PSA recognised this problem in its Report on sound recordings, ${ }^{52}$ recommending that the restrictions be removed "in relation to parallel imports from countries providing comparable levels of protection over the reproduction of musical works and sound recordings." 53 The SLCC's recommendation is reflected in the Act. ${ }^{54} \mathrm{New}$ Zealand's Copyright Amendment Act deals with the issue in subsection (5A)(b).

The Copyright Amendment Act (No 2) 1998 is more than a concession to availability, and is further reaching than the packaging amendment. Instead of refining the restrictions, it represents a fundamental policy reversal. Given the conceptual symmetry of the arguments between books and sound recordings, such as the anticipated effects of lower wholesale prices, increasing retailers' ability to compete with the internet, and increasing the availability of

49 The packaging amendment will most likely still be effective in Australia, as s 123(1) of the Trademarks Act 1995 has been interpreted by commentators as not preventing parallel importing. See Warwick A Rothnie "Gray Goods Billow onto the Open Main: s123 of the Trademarks Act 1995" (1996) 7 AIPJ 87, 88 and Paul Omaji "Infringement by Unauthorised Importation under Australia's Intellectual Property Laws" (1997) 10 EIPR 563, 569.

50 The Act received royal assent on 30 July 1998.

51 Copyright Amendment Bill (No.2) 1997 Parliament of Australia Parliamentary Library / Bills Digest No.197 1997-98 <http://www.aph.gov.au/library/pubs/bd/1997-98/>(last modified 28 July 1998) Bills Digest.

52 Price Surveillance Authority Inquiry into the Prices of Sound Recordings - Final Report (Canberra, Australia, December 1990), [Sound Recordings].

53 Sound Recordings above n 52, 160.

54 Copyright Amendment Act (No 2) 1998, inserting s 10AA into the Copyright Act 1968. 
titles, ${ }^{55}$ it is interesting that the restriction has been lifted for sound recordings only. As with books, this amendment is a response to the PSA's findings that Australian sound recording prices were higher than in other countries, including the United States, the United Kingdom, Canada, and New Zealand. ${ }^{56}$ The PSA recommended in both 1989 and 1995 that the ban on parallel imported books be completely removed, but this was rejected by the Australian Government. ${ }^{57}$

As with books, the PSA rejected the majority of the music industry's claims on the premise of increasing consumer welfare in terms of price and availability. Its decision acknowledged the possibility of increased piracy, the argument with perhaps the greatest force against the sound recording amendment. The music industry argued that if parallel imports were permitted, this would make customs' task of detecting pirated goods more difficult, and would introduce a need to prove the difference between parallel imported and pirated works. In practice both these requirements may prove difficult. The difficulty also lies in the consumer's inability to distinguish between genuine parallel imported products and pirated goods, as the quality is often identical. This argument has merit, but was rejected by the PSA which felt that even with a restriction in place, it is difficult to detect pirate or parallel imported copies, concluding. 58

...it is difficult to see why detection of pirate imports from legitimate records within Australia would be much more difficult under an open market than detection of pirate/parallel imports under a closed market.

The Act addresses these piracy concerns by imposing substantially increased penalties, ${ }^{59}$ and puts the onus on the importer to prove the goods are not infringing copies. ${ }^{60}$ The New Zealand Copyright Amendment Act also increases fines for importing an infringing copy, up

55 These are the purposes behind removing the restriction stated in the Explanatory Memorandum of the Copyright Amendment (No. 2) Bill 1997.

56 Sound Recordings above n 70, 83

57 "Bailey's, Bottles and Bills" above n 22, 22.

58 Sound Recordings above n 52, 158

59 Proposed s 132(6A) provides for fines of up to A\$55 000 or up to 5 years imprisonment for individuals, or a fine of up to $\mathrm{A} \$ 275000$ for corporations.

60 Copyright Amendment Act (No 2) 1998, schedule 1 item 6, inserting s 130A into the Copyright Act 1968. 
to $\$ 150000$, or up to three months imprisonment, ${ }^{61}$ but perhaps shortsightedly leaves the onus on the industry concerned to prove piracy.

\section{SHOULD NEW ZEALAND CONSIDER THE AUSTRALIAN APPROACH OR CONTINUE WITH ITS OWN PATH?}

The arguments considered in Part IV have varying strength depending on, for instance, the level of post sales support needed, and the capacity to pirate the good. Different products may therefore warrant different considerations. The NZIER Report's findings illustrate New Zealand market characteristics for the three markets it selected. Unfortunately, it did not consider relaxing the parallel importing restrictions in a similar manner to that proposed in Australia. Its narrower focus only considered the welfare implications of removing the prohibition completely. This section applies the reasoning of Parts IV and V to New Zealand products, and considers whether the Australian approach may be appropriate here.

\section{A Books}

\section{Price and availability}

The Report considered several welfare indicators, primarily the impact of lifting the restriction on prices and availability. It concluded that New Zealand book prices are on average, higher than those in the United States, the United Kingdom and Australia, ${ }^{62}$ and that allowing parallel importing would lead to a reduction in price for both popular and nonmainstream titles. This was the same finding made by the PSA regarding Australian prices. Interestingly, the Report looked at the effects of the Australian amendment, section $44 \mathrm{~A}$, and found that in fact, prices had not fallen significantly. ${ }^{63}$ This is likely to be due to the nature of the amendment. Allowing parallel importing of unavailable titles alone does not attack any possible price discrimination. Therefore, if the primary aim in New Zealand is to reduce prices, then an "availability amendment" alone may be inadequate.

Another key finding regarded availability of books - if the prohibition was lifted, then there may be development of niche bookshops to cater for non-mainstream titles. This is an availability argument. The Report found that availability of titles in Australia had improved:

61 New Zealand Copyright Amendment Act 1998, s 6(1), amending s 131(5) of the Copyright Act 1994.

62 Average book price NZIER internet search (\$NZ) NZ \$25.57, Australia \$22.66, UK \$22.96, US \$16.58. This figure varies constantly due to exchange rate fluctuations.

63 Parallel Importing: A Theoretical And Empirical Investigation above n 4, 47. 
"[a]n evaluation of [section 44A] showed that titles were being released much quicker into the Australian market."64 The Report predicted a similar effect in New Zealand: "[t]he overall impact on the availability of the material from a removal of the parallel importing restriction is again uncertain but is likely to lead to a greater range of books". ${ }^{65}$ This is especially likely for non-mainstream overseas material, in terms of speed of availability.

\section{Other market characteristics}

The Report made other key findings relevant to the issue as a whole. It found that a key feature of the book market is the ability of retailers to return unsold books, and that an unrestricted capacity to parallel import would end this practice. This would transfer the risk of unsold stock from the publisher or distributor to the retailer. This means the availability of books may actually fall, as retailers become more cautious over the range of titles they stock. This effect may be offset by the development of niche bookshops. The Report was inconclusive as to the effects of lifting the restriction on the domestic publishing industry. It simply concluded that a divergence of opinion existed between New Zealand publishers or distributors and retailers.

\section{Is an "availability amendment" sufficient?}

The Report estimated annual deadweight efficiency losses from the restrictions conservatively as $\$ 550,000$. For such a small anticipated effect, removing the restrictions altogether seems drastic. If an "availability amendment" was adopted, similar to that adopted in Australia, the positive effects described above could generally be obtained. The negative effects described could partially be avoided, as these occur where the parallel imported books undercut the authorised distributor. By definition, an "availability amendment" would not do this, as the books are not domestically available. The incentive to overseas authors to create original works would not be reduced, given that a royalty is still paid on parallel imported products.

Authorised distributors are unlikely to withdraw the "return ability" that currently benefits retailers if their own sales are not being undercut. Therefore authorised distributor's profits should only decrease through lost sales from other titles generally. An "availability amendment" would not undermine their incentives to operate here, and may even cross-

64 Parallel Importing: A Theoretical And Empirical Investigation above n 4, 47.

65 Parallel Importing: A Theoretical And Empirical Investigation above n 4, 47. 
subsidise the local publishing industry. However, an "availability amendment" alone would not see price falls that the Report anticipated from a wholesale lifting of the restrictions.

The relevant issue then involves identifying the primary objective - to promote availability or reduce price. In enacting the Copyright Amendment Act, the New Zealand government has either implicitly downplayed the potential negative effects on this particular market, such as the return ability and the potential effects on the domestic publishing industry, or has considered potential price reductions its primary concern. The latter seems more apparent. There is no reason why this type of "availability amendment" cannot apply to other products, however this was not explicitly considered in the NZIER report.

In the United Kingdom, the Net Book Agreement formed in 1957, provided a form of resale price maintenance for books. It was an agreement between publishers to prevent retailers from selling Net books at prices less than the net price set by publishers. The rationale was based on the special characteristics of the book market at that time. It aimed to assist smaller bookshops compete with larger outlets, and facilitate the maintenance of a wider range of titles. In 1997, the major publishers pulled out of the Agreement. This was because the underlying economic justifications to support it no longer existed. The existence of distribution networks and enhancements in printing technology to enable smaller print runs meant smaller bookstores were no longer disadvantaged. From an economic perspective, books should therefore be regarded as no different from other products in the marketplace. The abandonment of this form of resale price maintenance is consistent with the effect of the Copyright Amendment Act - generating lower prices and greater ease of distribution. It may lead to more books in New Zealand being sourced from the United Kingdom.

\section{B Music Compact Discs}

A direct comparison is possible between the NZIER Report and the Copyright Amendment Act (No 2) 1998. Both abandon parallel importing restrictions for sound recordings. Whether any significant difference exists between the New Zealand and Australian markets will help to evaluate the New Zealand approach.

The Report's international price comparison did not show New Zealand prices were consistently higher than those in the United States, the United Kingdom, Australia and 
Germany, ${ }^{66}$ but revealed that New Zealand prices could even rise if New Zealand's import ban was lifted.$^{67}$ As analysed above, this differs from the PSA's conclusions in Australia.

The second difference between New Zealand and Australia regarding music recordings relates to pirated copies. The Report recognised the PSA's argument that detection problems exist regardless of whether parallel imports were prohibited as being valid in Australia, but accorded it less weight in New Zealand. In Australia, pirated copies can viably be domestically produced. In New Zealand, the smaller market makes it less attractive to pirate domestically. Therefore, as pirated goods are imported into New Zealand, rather than being domestically pirated, they would be more easily detected in New Zealand than in Australia, for example, through customs.

Previously, the New Zealand Customs Service has had to detect both parallel imports and pirated copies, ${ }^{68}$ as both were prohibited. Therefore, it has not strictly needed to distinguish between parallel imports and pirated goods. New Zealand's Copyright Amendment Act makes Customs' task more difficult, as it is now required to strictly distinguish between them. This is compounded by the expected increase in volume of parallel imports. Therefore, removing the prohibition would make it more difficult to detect pirated copies in New Zealand, or to distinguish them from parallel imports. This is the precise argument that the PSA rejected in Australia. The Report cited this "piracy" argument as "of considerable importance" 69 for not lifting the prohibition.

Therefore, two differences exist regarding sound recordings between New Zealand and Australia - the price effect and piracy. These may justify a more cautious approach to sound

66 Average prices - NZIER internet search (\$NZ, exchange rates as assumed by the NZIER) NZ (CD Net) \$30.38; US (AB CD's) \$23.53, (CD World) \$31.98, (CDNOW) \$22.30, (Tower) \$23.53; Australia (Reddog) \$32.78; UK (Music Stop) \$33.73; Germany (TeleCD) \$30.09. At exchange rates as at 16/1/98: NZ (CD Net) \$30.38; US (AB CD's) \$25.60, (CD World) \$34.78, (CDNOW) \$24.25, (Tower) \$25.59; Australia (Reddog) \$33.15; UK (Music Stop) \$39.68; Germany (TeleCD) \$32.72.

67 Parallel Importing: A Theoretical And Empirical Investigation above n 4, 55.

68 Under the Copyright Act 1994 s 140, Customs can detain pirated goods if notice requesting the detention of pirated copies has been filed with the New Zealand Customs Service under s 136 and the Copyright (Border Protection) Regulations 1994. Similarly, Customs must notify copyright owners if parallel imported goods are pending, where the appropriate notice has been given to Customs under both the Copyright Act 1994 s 144, and under the Copyright (Parallel Importing Notice Fee) Regulations 1995.

69 Parallel Importing: A Theoretical And Empirical Investigation above n 4, 59. 
recordings than that contained in the Copyright Amendment Act (No 2) 1998, and certainly a more cautious approach than the New Zealand Copyright Amendment Act 1998. The latter Act seems to rely on financial deterrence to solve piracy concerns.

If there is no justification for altering the restriction on grounds of price and a good argument for retaining the restrictions on grounds of piracy, are there any arguments to be made in terms of an "availability amendment"? Conceptually, as arguments regarding books and CDs should be similar - the ability to source non-mainstream materials - an "availability amendment" could be expected to be beneficial. However, the Report's conclusion for sound recordings differs from that for books. It stated that it was not clear that lifting the restriction for sound recordings would change the availability of non-mainstream titles from small record labels. Frustratingly, no reason is offered for this inconsistency.

Given these findings, especially the differences between New Zealand and Australia described above, it must be questioned whether any real benefits would be obtained from abandoning or even reducing the scope of its parallel importing restriction for sound recordings in New Zealand. In terms of overall welfare, the Report identified the annual deadweight efficiency loss from maintaining the restrictions as only $\$ 195,000$, yet concluded that lifting the restrictions would be beneficial for overall economic welfare. It based this on a finding that prices are likely to fall by $\$ 3$ per $C D .{ }^{70}$ However, this is contrary to its own survey that New Zealand prices are comparatively similar to those internationally. It seems even more inconsistent that the Report recommended removing the restrictions given that no increase in availability was anticipated. The recommendation was premised on the grounds that availability was "unlikely to get any worse". This hardly seems a sufficient justification for the complete removal of the parallel import restriction for sound recordings. It is even more remarkable that this reasoning was generalised to justify lifting the restriction for all goods.

\section{Motor Vehicles}

The used motor vehicle market is unique in New Zealand. It has operated as if no parallel importing restrictions were in place since the removal of import licensing restrictions in 1989. This market provides empirical evidence of the effect of parallel imports. It verifies many of the arguments described in Part IV.

The Report found that consumers have benefited from this increased competition, in terms of price, selection of vehicles and speed of release into the market. However, odometer 
scandals in 1997 highlighted the quality assurance problem. The Report concluded that it is not clear that parallel importing restrictions are necessarily the best way to deal with concerns about quality and safety standards, ${ }^{71}$ and tighter checking of imports would "virtually eliminate this [safety] argument." ${ }^{12}$ Regarding after sales service, the Report found that there "does not appear to be any shortage of independent providers". ${ }^{73}$ Therefore, parallel imported products can still be serviced, although the Report acknowledged that parallel importers' free riding on the authorised distributor's warranty provisions was a legitimate concern. These concerns are specific to functional goods, and as indicated in Part IV, can be reduced by effective labelling and consumer education.

The effect on authorised distributors has mainly been through tariff removals, but the availability of used imports has acted as a check on their margins. Quantitatively, the Report's analysis indicated a significant net welfare gain of $\$ 590$ million to society since 1989 .

\section{The Characteristics of Individual Goods}

The most effective approach to parallel importing may theoretically depend on the characteristics of each individual good or market. For example, the Report's surveys revealed price discrimination was more prevalent in the motor vehicle industry than the other two markets. Motor vehicles may also require more post-sales servicing. These are the considerations discussed in Part IV. However, if a "piecemeal" market-by-market approach of having different restrictions for different goods is taken too far, it could disrupt the coherency and structure of the parallel importing regime. The proposed (at the time) Australian regime is criticised on this basis as "...there will be no less than three discrete regimes of treatment of importation under the Copyright Act: one for books, one for recorded music, and one for other forms of intellectual property, including software. ${ }^{174}$ This could be further complicated by the

71 Parallel Importing: A Theoretical And Empirical Investigation above n 4, 39.

72 Parallel Importing: A Theoretical And Empirical Investigation above n 4, 39.

73 Parallel Importing: A Theoretical And Empirical Investigation above n 4, 33.

74 Brett Cottle, Chief Executive of the Australasian Performing Rights Association, evidence to Senate Legal and Constitutional Committee, 4 February 1998, Hansard, 57. Cited in Bills Digest, above n 51, 4. 
packaging legislation. The Australian music industry has criticised the Copyright Amendment Act (No.2) 1998 for singling out products, rather than being driven by economic principle: ${ }^{75}$

If the economic principle itself were being pursued in regard to copyright items, then this bill should properly have just covered the gamut of copyright items. If it is the economic principle that is at stake, copyright covers books, movies, CD-ROMs, computer programs, sound recordings and musical works.

This criticism refers to only "traditional" copyright works. It implicitly assumes all such copyright works have similar market characteristics, or that it is more important to have a consistent treatment between them. If the aim is to strictly protect intellectual property rights, then parallel importing should have remained prohibited. However, if the aim is to enhance consumer welfare, an approach based on characteristics such as availability and price will achieve this. If copyright is going to be used for the many different types of goods its present scope encompasses, such as motor vehicles, it can make rational economic sense for different rules to apply. The real difficulty is a practical one. Assessing and monitoring individual markets or even categories of markets would constitute an unjustifiable use of resources. It also has significant potential to devolve a myriad of different rules which could become unmanageable. Interesting issues arise regarding categorisation of products under such an approach. Multimedia works, for example, could contain films, literary works and sound recordings in one physical article. Under a "market-by-market" approach, different parallel importing rules could exist for each of these categories. No simple solution is apparent for this situation.

This may be an exceptional scenario. Making concessions based on availability and packaging generally would not disrupt the coherency of the restriction, because the concession could apply to all products equally. The Report did allude to the sense of the Australian Copyright Amendment Act, stating "it is most difficult to see the welfare gain resulting from a restriction on parallel imports for goods where the copyright subsists only in the label or packaging of the substantive good". ${ }^{76}$ Instead, in New Zealand the legislature adopted a more radical path. In enacting the Copyright Amendment Act, the New Zealand Government has

75 Emmanuel Candi, Executive Director of the Australian Record Industry Association, evidence to Senate Legal and Constitutional Committee, 3 February 1998, Hansard, 18. Cited in Bills Digest, above $n 51,3$. 
implemented the Report very literally, and has generalised the analysis of the three surveyed markets to all goods.

Functional goods remain a difficult consideration. For instance, it seems anomalous that copyright can be used to restrict distribution of doorknobs. ${ }^{77}$ A judicious compromise could be to apply an expanded packaging/labelling type amendment. As analysed earlier, the Australian Copyright Amendment Act would not be broad enough to encompass graphics on a jetski. A wider amendment could be possible, for example, allowing parallel importing if the copyright item is not specifically related to the functioning of the article. An exception based on such criteria could become difficult to apply. Computer software immediately presents itself as an example. A more contentious, but more workable solution could be, in addition to a labelling type amendment, to permit the parallel importation of functional three dimensional "industrially applied" objects, as currently defined in section 75(4). This avenue would place pressure on the definition of "industrially applied", but appears to be a practical solution. ${ }^{78}$

It is a pity the Report did not draw more fully on the Australian approaches outlined above, as policy considerations between countries are relatively similar. ${ }^{79}$ They are both small, geographically isolated markets. New Zealand's Copyright Amendment Act is based largely on the Report's findings that abandoning the prohibition would lead to welfare increases. It is much more dramatic than the more cautious incremental Australian approach, which seems to consider the issues for each market. The Australian approach limits reforms to circumstances where policy reasons make granting an importation monopoly undesirable. The current New Zealand approach attempts to maximise the advantages of free importation, whereas the Australian approach seeks to minimise the shortcomings of a prohibition.

\section{WHAT REMAINS TO BE DONE UNDER THE NEW ZEALAND ACT?}

\section{A Further Legislative Changes}

Copyright is not the sole mechanism to prevent parallel imported goods. The Trademarks Act 1953 and the Patents Act 1953 may prohibit parallel imports when the courts adopt a

77 Halliday v Hafele (NZ) Ltd (5 March 1998), unreported, High Court, Auckland Registry, M1797/97.

78 Note that New Zealand's copyright protection of such products is greater than required under TRIPS (See above n 3). This is partially recognised in the Copyright Amendment Act in subs (5A)(b)(iii).

79 Except, for example as to piracy. 
territorial interpretation. ${ }^{80}$ The Trademarks Act provides the exclusive right "to use ${ }^{\prime 11}$ the mark, and the Patents Act provides a similar right "to vend". Many products contain at least one of these rights. Normally these rights expire on the first sale of the goods, but under a territorial interpretation, this first sale is interpreted as being the first sale in New Zealand. Trademark law lends itself to a territorial interpretation as registration occurs separately in each country. Given that a mark is registered in New Zealand, importation can be treated as a "use" upon the goods, even if the mark is lawfully applied to the goods in the source country. ${ }^{82}$ This is because trademarks may be owned by one company in New Zealand, and by an unrelated company overseas. Therefore, even if the genuine goods were made with the consent of the trademark owner in the country of origin, importation without permission of the New Zealand trademark proprietor could still infringe the New Zealand trademark. The potential defence contained in section 8(3)(a) will not apply under a territorial interpretation because it is not the New Zealand registered proprietor who applied the mark or consented to the mark's use. Therefore, the New Zealand trademark proprietor would still possess the exclusive right to distribute.

If the Copyright Amendment Act is to have its anticipated economic effects, legislative changes may be needed to prevent parallel importing claims under these alternative avenues. As the amendment seems to be driven by economic concerns, rather than purely intellectual property difficulties, legislating to prevent actions under other legislation should not be a political barrier to the government.

If such changes do not occur, inconsistencies will exist between the statutes. Secondly, potential loopholes may exist. For example, under the Trademarks Act, there is no infringement if the trade mark has been removed from the parallel imported good. While this reduces the product's marketability, it may also create differences between goods from which it is possible to remove the trademark and those from which it is not. It seems artificial to be able to go to such lengths when the practice is no longer illegal under the Copyright Act. Thirdly, as analysed earlier, if a packaging/labelling type amendment were contemplated, the potential ability to use trademarks to prevent parallel importing would render the amendment futile. However, it is not as simple to amend the Trademarks Act to deal with the problem as it is to

80 The Layout Designs Act 1994 may similarly prevent parallel importing if the product contains integrated circuits, which includes silicon chips.

81 Trademarks Act 1953, s 8.

82 See South Pacific Tyres above n 33. 
amend the Copyright Act. This is because the Trademarks Act contains no express prohibition against parallel importing. The prohibition in the Trademarks Act is through applying core trade mark infringement principles, and to address parallel importing as the use of a mark may involve wider ranging consequences for the Act as a whole.

Even if such changes do occur, parallel importers may still be subject to other restrictions. The Fair Trading Act 1986 and the common law doctrine of "passing off" address potential deception by importers, once the goods are imported. These avenues may impose additional costs on parallel importers to differentiate their goods from those of the authorised distributor.

\section{B Regulatory Changes}

Regulatory enforcement must address the issues identified in Part IV. These include comprehensive and strict regulations on packaging and labelling of goods, identifying them as parallel imports, including the provision of any post-sales service or differences in quality. The Copyright Amendment Act will be self-defeating if it leads to consumer deception.

Another important task facing regulators is to prevent the import of pirated goods. Parallel imports will make these more difficult to detect in New Zealand, and an influx of pirated goods could damage the local music and computer industries. These industries will already struggle given the likely effects of the Copyright Amendment Act. The increased penalties contained in the Act will help prevent piracy, but vigorous customs control is still necessary.

\section{CONCLUSION}

This discussion has examined the rationale behind parallel importing restrictions, the consequences of the Copyright Amendment Act 1998, and identified some alternative options that were available. The issue involves choosing between both competing interests, and several opposing theoretical viewpoints. The most fundamental choice is whether policy choices are made from the perspective of economic objectives or the upholding of strict intellectual property rights.

In enacting the Copyright Amendment Act, the legislature has accepted the theoretical economic rationales for removing the prohibition. This has altered the interface between intellectual property and competition law. These rationales favour a removal of the restrictions, especially for functional goods, although the arguments do lose some force given the relatively inconclusive data presented by the NZIER report. The defects identified in the pre-Copyright Amendment Act framework were not beyond remedy. Modification of the prohibition could have consisted of an approach similar but not necessarily identical to that adopted in Australia. 
Amendments to facilitate product availability and removing restrictions where the sole reason for the restriction is by virtue of packaging or labelling could alleviate pressing problems. These were overlooked in the Copyright Amendment Act, as they do not attack price discrimination.

The discussion has illustrated how an analysis of parallel importing may differ when the type of product differs, whether it is functional or not, and when its characteristics of price and availability vary. However, it may be logistically impractical to justify differing restrictions based on individual characteristics. The Copyright Amendment Act may be regarded as "an all or nothing" approach, removing the restriction for all types of goods. This is administratively expedient, but conceptually less satisfying. Ultimately, the Act was driven by a clear policy choice, a choice consistent with economic deregulation in general, and free trade in particular. From this trade perspective, the correct approach was taken. Those who view intellectual property rights as paramount would advocate the more restrained Australian approach. Possibly the only way to see whose argument is stronger is to see what the newly open market delivers. 